\title{
Education in practice
}

\section{How to manage: patient with a low faecal elastase}

\author{
Kwan Wai Lam, John Leeds
} Pancreaticobiliary Medicine,
Freeman Hospital, Newcastle upon Tyne, UK

\section{Correspondence to}

Dr John Leeds, Pancreaticobiliary

Medicine, Freeman Hospital, Newcastle upon Tyne NE7 7DN, UK; j.leeds@nhs.net

Received 23 July 2019 Revised 31 October 2019 Accepted 4 November 2019 Published Online First 15 November 2019

\section{Check for updates}

(C) Author(s) (or their employer(s)) 2021. No commercial re-use. See rights and permissions. Published by BMJ.

To cite: Lam KW, Leeds J. Frontline Gastroenterology 2021;12:67-73.

\section{INTRODUCTION}

Pancreatic exocrine insufficiency (PEI) is underdiagnosed; however, the use of the faecal elastase-1 (Fel-1) test is common and recommended in the investigation of gastrointestinal symptoms. The Fel-1 test has been validated against a number of other tests of exocrine pancreatic function but often in very specific circumstances. If used routinely in gastrointestinal practice, an abnormal result will frequently occur but this cannot be assumed to mean that the patient has PEI. This finding should prompt the clinician to arrange further investigations to identify whether there is evidence of primary PEI, secondary PEI or whether there is another reason why the Fel-1 level is low. This review will provide an overview of Fel-1 testing, propose relevant investigations and discuss the potential pitfalls around management.

\section{FEL-1 OVERVIEW}

Fel-1 is the most commonly utilised test in the UK for assessing exocrine pancreatic function and is recommended for investigation of chronic diarrhoea. ${ }^{1}{ }^{2}$ Fel-1 is a proteolytic enzyme secreted by the exocrine pancreas and accounts for about $6 \%$ of total enzyme output. ${ }^{3}$ Elastase- 1 binds to bile salts and minimally degraded during passage through the gastrointestinal tract and is chemically stable in faeces for up to a week at room temperature. $^{4}$ Compared with direct tests, Fel-1 is simple to perform, non-invasive and more cost-effective. ${ }^{5}$ Multiple studies have shown good correlations between Fel-1 level and pancreatic enzyme output including amylase, trypsin and lipase. ${ }^{4-6}$ Fel-1 has been compared with other indirect tests and is superior to faecal chymotrypsin, ${ }^{246}$ faecal lipase, ${ }^{7}$ the $13 \mathrm{C}$ mixed triglyceride breath test ${ }^{8}$ and the pancreolauryl test. ${ }^{9}$
Most laboratories report an abnormal level as $<200 \mu \mathrm{g} / \mathrm{g}$ stool; however, there are a number of caveats and pitfalls concerning a single sample and therefore a low level does not always indicate PEI. Borderline results $(200-250 \mu \mathrm{g} / \mathrm{g})$ should be considered for retesting and further investigations initiated. Fel-1 values should be interpreted with caution when the specimen is watery as dilution can result in false-positive results. This limitation can be addressed by lyophilisation of the stool sample or centrifugation to reduce the water content. ${ }^{10}$

A recent review showed that Fel-1 has a good negative predictive value, meaning a value $>200$ largely excludes a pancreatic cause for symptoms. ${ }^{11}$ This is not universal as there are patients with chronic pancreatitis with adequate remaining parenchymal cell volume and are exocrine sufficient. Follow-up for relevant symptoms and repeat Fel-1 testing is important in these individuals. It must be remembered that Fel-1 is a test for PEI, which is not interchangeable with chronic pancreatitis. A recent study showed a high prevalence of abnormal Fel-1 levels in all patients referred to secondary care gastroenterology clinics $\left(13.1 \%<200 \mu \mathrm{g} / \mathrm{g}\right.$ stool). ${ }^{12}$ In those with a low Fel-1, only one-third had abnormal pancreatic imaging although the majority showed a response to open-labelled pancreatic enzyme replacement therapy (PERT). ${ }^{12}$

A low Fel-1 may indicate that the cause of symptoms may be due to a pancreatic cause and should prompt further investigations to identify this rather than only treat with PERT. Box 1 shows the causes of a low Fel-1 and figure 1 shows the mechanisms of a low Fel-1. Making a diagnosis of PEI requires more than a single abnormal Fel-1 level and includes assessment of the patients' symptoms, 


\section{Box 1 Causes of a low faecal elastase-1}

Abnormal pancreatic imaging:

- Chronic pancreatitis (aetiology defined as per the TIGARO (riteria) ${ }^{65}$

- Pancreatic tumours including cystic disease

- Pancreatic resection

- Pancreatic atrophy

- Acute pancreatitis

- Congenital absence (often associated with absence of left kidney) or malformation (eg, annular pancreas)

- Genetic causes, for example, cystic fibrosis, ShwachmanDiamond syndrome

Normal pancreatic imaging:

- Spurious result-watery diarrhoea

- Coeliac disease

- Diabetes mellitus

- Bile acid diarrhoea

- Irritable bowel syndrome

- Inflammatory bowel disease

- Small bowel bacterial overgrowth

- HIV infection and antiviral drugs

- Rheumatological disorders

- Chronic kidney disease

- Use of orlistat

nutritional status, risk factors for pancreatic disease, endocrine function and structural imaging.

\section{INITIAL PATIENT ASSESSMENT (SYMPTOMS, RISK FACTORS AND NUTRITIONAL STATUS)}

Diagnosing PEI is clinically challenging due to its nonspecific symptoms especially at an early stage and is often underdiagnosed. ${ }^{1314}$ PEI can occur in the absence of abnormal pancreatic imaging, and therefore, assessment of the pancreas alone is not sufficient. A patient with PEI would be expected to be malabsorbing fat but true steatorrhoea is not always seen and patients commonly describe diarrhoea. ${ }^{12}$ One of the most useful symptoms is floating, difficult to flush away stool. ${ }^{15}$ Weight loss is a common symptom due to fat malabsorption and is commonly associated with deficiencies of fat-soluble vitamins particularly vitamin D. A recent review showed that in patients with chronic pancreatitis the prevalence of abnormal vitamin $\mathrm{A}$ is $16.8 \%$, vitamin D is $57.6 \%$ and vitamin $\mathrm{E}$ is $29.2 \%$. Vitamin $\mathrm{K}$ has been poorly evaluated. ${ }^{16}$ Abdominal pain and bloating are also common symptoms of PEI but have cross-over with functional bowel disorders. ${ }^{17}$ Some patients with PEI initially appear to present with symptoms akin to diarrhoea-predominant irritable bowel syndrome. ${ }^{18}$

Baseline weight and body mass index can be helpful but should not be relied on and emphasis should be placed on change in weight over time. Patients with PEI can initially be overweight or even obese leading to false reassurance. In patients with chronic pancreatitis, obesity is an independent risk factor for development of diabetes. ${ }^{19}$ Accurate documentation and comparison of previous weights can be helpful to show significant weight loss, which is also associated with poorer outcomes and complications such as sarcopaenia and abnormalities of bone mineral density. If available, assessment of anthropomorphic measures such as tricep skin-fold thickness and hand grip strength could be considered.

Questioning around alcohol intake is clearly relevant but emerging evidence suggests that smoking is potentially more toxic to the pancreas and should be specifically targeted. ${ }^{20}$ Family history of pancreatic disease particularly before the age of 40 should raise concern about hereditary pancreatitis. Other conditions that may cause PEI, or are risk factors for pancreatic diseases, also have a familial disposition such as lipid disorders, gallstones, diabetes and coeliac disease.

Medication history is also relevant as some have been associated with pancreatic damage (eg, azathioprine $)^{21}$ but also can cause gastrointestinal symptoms similar to PEI (eg, orlistat).

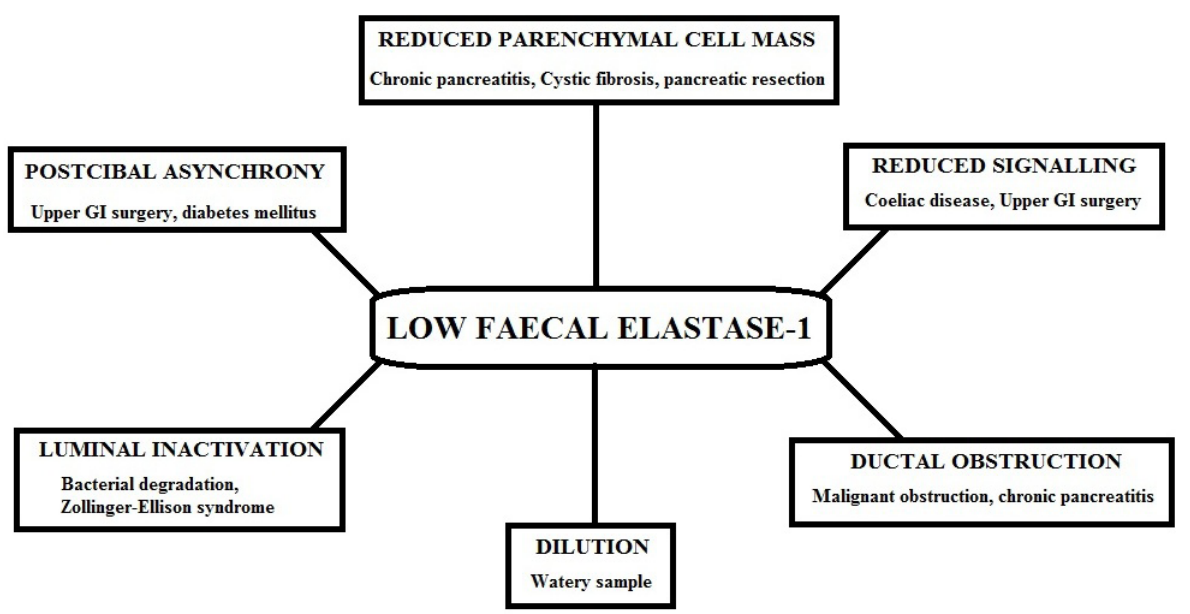

Figure 1 Mechanisms of a low faecal elastase (with examples). Gl, gastrointestinal. 


\section{RELEVANT INVESTIGATIONS}

A single abnormal Fel-1 level is insufficient to make a diagnosis of PEI and the next step is not simply to 'have a trial of PERT' for which there is not good evidence. The whole patient picture needs to be put together including further investigations to identify whether this is primary PEI (caused by an underlying pancreatic disease), secondary PEI (due to non-pancreatic conditions) or spurious (false positive). This appears to contradict the knowledge on Fel-1 in particular Fel-1 $<100$, which has been shown to have a high sensitivity and specificity. The validation studies for Fel-1 were in patients with well-documented exocrine pancreatic diseases such as chronic pancreatitis and cystic fibrosis. ${ }^{5-7}$ If the population being tested is then changed to general gastroenterology referrals (where the pre-test probability of underlying PEI is lower), then this changes substantially and the numbers with a false positive will be larger. ${ }^{11} 12$ Furthermore, there is variation of Fel-1 levels within one stool passage and from day-to-day within the same individual that can cross the normal/abnormal cut-off. ${ }^{22}$ Therefore, patients with mild symptoms, normal nutritional status, no pancreatic risk factors and/or borderline Fel-1 levels $(150-250 \mu \mathrm{g} / \mathrm{g}$ stool) should be considered for repeating the Fel-1, assessment for other gastrointestinal conditions and only proceeding to further pancreatic tests if Fel-1 remains abnormal.

For those in whom further investigations are warranted, cross-sectional imaging of the pancreas should be performed using either triple-phase pancreatic protocol CT or MRI depending on the patients age and concern about ionising radiation exposure. $\mathrm{CT}$ is most useful for gaining information about the pancreatic parenchyma, whereas an MRI gives better information about the ductal system. Clear abnormalities on CT scanning such as changes consistent with chronic pancreatitis or a mass lesion should lead to appropriate management including PERT. ${ }^{23}$ Pancreatic atrophy is challenging, subjective and affected by some conditions such as diabetes as well as advancing age. ${ }^{2425}$ A dilated pancreatic duct may indicate obstruction downstream or more subtle chronic pancreatitis in which case an MRI/magnetic resonance cholangiopancreatography (MRCP) should be considered. In some circumstances, the addition of secretin stimulation at the time of MRCP increases the sensitivity for subtle changes or strictures in the pancreatic duct but this is not universally available in the UK. ${ }^{26} 27$

If the pancreas appears normal on cross-sectional imaging but the patient has significant diarrhoea, weight loss or risk factors for pancreatic disease, then an endoscopic ultrasound (EUS) can help to detect chronic pancreatitis or small tumours. ${ }^{28}$ EUS is more sensitive than cross-sectional imaging for lesions $<2 \mathrm{~cm}$ and can pick up subtle changes in the pancreatic parenchyma denoting fibrosis. ${ }^{28}$ The Rosemont criteria are used to determine whether there are sufficient features to diagnose chronic pancreatitis. ${ }^{29}$

Patients with some features but not enough to clinch the diagnosis should be followed up and undergo imaging review. Perhaps, the most useful aspect of EUS is its very high negative predictive value meaning that patients with no criteria have a very low risk of having chronic pancreatitis. ${ }^{29}$ Ideally, a more specific test for PEI could be employed to either confirm or refute the diagnosis such as the $14 \mathrm{C}$ mixed triglyceride breath test, the coefficient of fat absorption or a direct test such as the secretin-caerulein test; however, these are not routinely available in the UK.

In those with no structural changes on cross-sectional imaging and EUS but there is evidence of PEI (eg, weight loss and/or steatorrhoea) then investigations for secondary PEI should be undertaken. Most of these conditions can be identified using the British Society of Gastroenterology (BSG) guidelines for investigation of chronic diarrhoea. ${ }^{1}$ Figure 2 suggests a management algorithm for patients presenting with a low Fel-1 with relevant investigations for causes of secondary PEI.

\section{INVESTIGATING FOR SECONDARY PEI}

Secondary PEI is seen in conditions that lead to reduced exocrine pancreatic enzyme production or effectiveness but where the pancreas is not the primary pathology. The following section describes those conditions that have been shown to lead to a reduced Fel-1.

\section{Coeliac disease}

The most well documented of these is coeliac disease, which may lead to PEI by a number of mechanisms. Villous atrophy may lead to reduced production of cholecystokinin from the duodenum, thereby reducing pancreatic output. ${ }^{30}$ Similarly, increased levels of plasma peptide YY (which inhibits pancreatic output) have been found in coeliac disease. ${ }^{31}$ This is further substantiated by studies using secretin stimulation showing normal pancreatic output suggesting a signalling problem. Several studies in both paediatric and adult cohorts have confirmed a high prevalence of PEI, particularly with ongoing diarrhoea despite a glutenfree diet, with good response to PERT. ${ }^{32}{ }^{33}$ Some patients appear to recover exocrine function over time and may not need lifelong PERT. ${ }^{34}$ Fel-1 levels were not related to coeliac serology or degree of residual villous atrophy. ${ }^{33} 34$

\section{Inflammatory bowel disease}

There is an increased risk of developing chronic pancreatitis in patients with inflammatory bowel disease (IBD), which increases over time. ${ }^{35}$ The reasons for this are likely to be multifactorial including co-existence of gallstone disease, medications such as steroids and azathioprine, autoimmunity and smoking. ${ }^{35}$ The true prevalence of PEI in patients with IBD is 


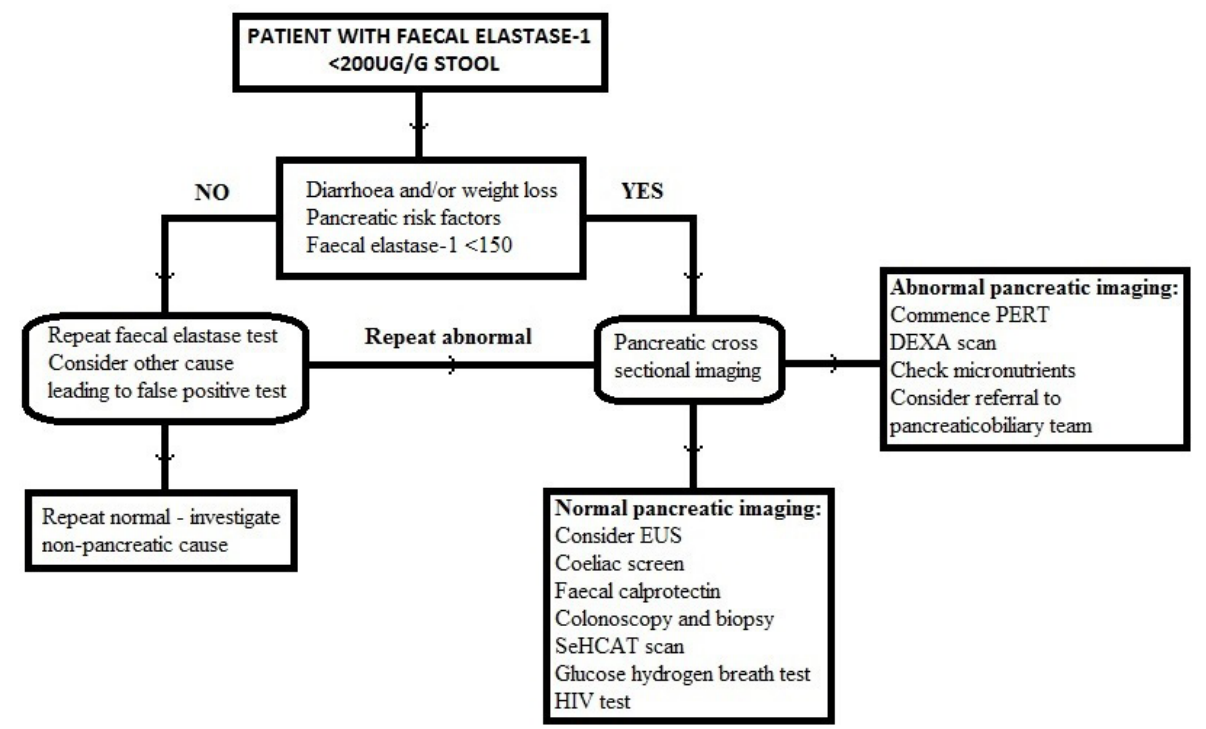

Figure 2 Management algorithm of a patient with a low faecal elastase-1. DEXA, ual energy X-ray absorbtiometry; dual energy X-ray absorbtiometry; EUS, endoscopic ultrasound; PERT, pancreatic enzyme replacement therapy.

unknown; however, clinically symptomatic PEI may be unrecognised and treated as disease activity. Two previous studies have shown a higher than expected prevalence of PEI in patients with IBD with about $10 \%$ of patients having abnormal pancreatograms on MRI scanning. ${ }^{36}$ PEI was associated with increased stool frequency, softer stools, active disease, previous surgery and duration of IBD $>10$ years. ${ }^{37}$ Neither of these studies investigated to the value of PERT in these populations and some of the Fel-1 levels could be false positives. The group to target would be those patients with continued diarrhoea, mucosal improvement and low inflammatory markers.

\section{Diabetes mellitus}

There is a well-established relationship between the endocrine and exocrine pancreas. ${ }^{38}$ Diabetes due to diseases of the exocrine pancreas has been designated as type $3 \mathrm{c}$ by the American Diabetes Association and is associated with insulin deficiency but also reduced glucagon production. $^{39}$ Development of type $3 \mathrm{c}$ diabetes occurs increasingly in patients with chronic pancreatitis but also some patients with type 1 and type 2 diabetes have been shown to have alterations of exocrine function. The mechanisms are likely to be multifactorial including reduction of a trophic effect of insulin, autoimmune cross-over, reduced signalling due to autonomic neuropathy and disease of the pancreatic microvasculature. ${ }^{40-44}$ Studies have shown a very high prevalence of low Fel-1 in patients with type 1 diabetes $(26 \%-44 \%)$ and type 2 diabetes (12\%-20\%). ${ }^{45-48}$ Low Fel-1 levels have been associated with poorer glycaemic control and reduced BMI. ${ }^{45}$ In most of these studies, relevant symptoms were not reported and treatment with PERT was not investigated. Gastrointestinal symptoms are frequent in patients with diabetes compared with the general population with a recent study showing the prevalence of PEI in type 1 diabetes patients with diarrhoea being around $6 \% .{ }^{49}$ The only prospective, randomised study of PERT in patients with diabetes and low Fel-1 showed a reduction in the frequency of hypoglycaemia but again few patients had symptoms compatible with PEI. ${ }^{50}$ This makes interpretation of Fel-1 difficult in patients with diabetes as under-recognition is likely but Fel-1 may not be a good marker for PEI in patients with diabetes and may have confounding reasons for such high reported prevalence.

\section{Bile acid diarrhoea}

Bile acid diarrhoea is a common cause for chronic diarrhoea and can present with symptoms that mimic PEI. Coordination of biliary and pancreatic secretions is crucial for optimal fat emulsification and absorption. ${ }^{51}$ Despite Fel-1 and SeHCAT scanning being commonplace and recommended in national guidelines for the investigation of chronic diarrhoea, ${ }^{1}$ there are no data on co-existence of these conditions or the interrelation of these tests.

\section{HIV infection}

Gastrointestinal symptoms such as diarrhoea and weight loss are common in patients with HIV infection. Changes in the small intestine have been well described; however, the morphological degree of intestinal damage is often mild and may not be enough to explain severe fat malabsorption. ${ }^{52} 53$ Previous studies have shown a high prevalence of abnormal Fel-1 (54\%) with improvements in faecal fat loss following institution of PERT. ${ }^{54}$ Furthermore, some antiretroviral medications have been postulated to play a role in PEI due to the side effect of significant hypertriglyceridaemia. Didanosine in particular has been associated with lower levels of Fel-1 and symptomatic 
steatorrhoea. ${ }^{55}$ The prevalence of HIV in patients with PEI is unknown.

\section{Other conditions}

A number of other conditions have also been associated with PEI but definite benefit from treatment is yet to be proven in all cases. These are mentioned here briefly as they may muddy the waters when assessing a patient with a low Fel-1.

Increasing age has been shown to be associated with reduced pancreatic output but whether this is pathological is not fully known. ${ }^{567}$ Upper intestinal surgery, particularly Roux-en-Y, leads to changes in mixing of pancreatic secretions and food and has been shown to lead to PEI. ${ }^{58}$ Some studies have shown benefit of PERT in these settings by reducing weight loss and steatorrhoea. ${ }^{59}$

There have been some small studies in both chronic kidney disease and rheumatological disorders showing a significant prevalence of low Fel-1. In both of these areas, nutrition is vital and theoretically PEI would be important to identify and correct. No treatment studies have as yet been reported in these areas. ${ }^{60}$

\section{MANAGEMENT OF PEI}

PERT is the main pharmacological treatment for patients with PEI and has classically been undertreated. There is evidence that being seen by clinicians with expertise in pancreatic disease improves symptoms and quality of life. ${ }^{61}$ Starting doses should be at least 40000-50000 units of lipase per meal with the very real expectation of increasing to 80000-100000 units. Motivated patients can be taught to count the fat in their meals and take dynamically tailored PERT, which is best supervised by a dietitian. Patients whom have undergone upper intestinal surgery (particularly distal gastric resections) do not require enteric coated preparations. PERT should be taken across the meal for optimum digestion. ${ }^{62}$ Lack of response to PERT should lead to increase in the dose, check compliance, possibly add in a PPI and if all this fails revisit the initial diagnosis. ${ }^{63}$ Table 1 shows the commercially available formulations of PERT. Importantly, all currently available formulations are derived from a porcine source, which has implications for certain religious groups and vegetarians/vegans. Dispensation can be discussed with patients and a letter of support may be required. There are non-porcine enzyme products, which are expensive, not currently available on prescription and have unknown efficacy. A new non-porcine PERT (Sollpura) is in the advanced stages of clinical trials the results of which are awaited.

One major complication associated with PEI is fatsoluble vitamin deficiency. Routine checking of at least vitamin $\mathrm{D}$ should be undertaken and replaced if deficient. Patients with chronic pancreatitis, coeliac disease and IBD should be offered a dual energy X-ray absorbtiometry (DEXA) scan to assess for metabolic
Table 1 Commercially available formulations of PERT in the UK

\begin{tabular}{|c|c|c|}
\hline $\begin{array}{l}\text { Product and } \\
\text { formulation }\end{array}$ & Producer & Active ingredients \\
\hline $\begin{array}{l}\text { Creon } 10000 \\
\text { capsules }\end{array}$ & Mylan & $\begin{array}{l}\text { Amylase } 8000 \text { unit } \\
\text { Lipase } 10000 \text { unit } \\
\text { Protease } 600 \text { unit }\end{array}$ \\
\hline $\begin{array}{l}\text { Creon } 25000 \\
\text { capsules }\end{array}$ & & $\begin{array}{l}\text { Amylase } 18000 \text { unit } \\
\text { Lipase } 25000 \text { unit } \\
\text { Protease } 1000 \text { unit }\end{array}$ \\
\hline Creon microgranules & & $\begin{array}{l}\text { Amylase } 3600 \text { unit } \\
\text { Lipase } 5000 \text { unit } \\
\text { Protease } 200 \text { unit }\end{array}$ \\
\hline Nutrizym 22 capsules & Merck Serono & $\begin{array}{l}\text { Amylase } 19800 \text { unit } \\
\text { Lipase } 22000 \text { unit } \\
\text { Protease } 1100 \text { unit }\end{array}$ \\
\hline Pancrease HL capsules & Janssen Cilag & $\begin{array}{l}\text { Amylase } 22500 \text { unit } \\
\text { Lipase } 25000 \text { unit } \\
\text { Protease } 1250 \text { unit }\end{array}$ \\
\hline Pancrex V oral powder & $\begin{array}{l}\text { Essential } \\
\text { Pharmaceuticals }\end{array}$ & $\begin{array}{l}\text { Amylase } 30000 \text { unit } \\
\text { Lipase } 25000 \text { unit } \\
\text { Protease } 1400 \text { unit }\end{array}$ \\
\hline $\begin{array}{l}\text { Pancrex V } 125 \mathrm{mg} \\
\text { capsules }\end{array}$ & & $\begin{array}{l}\text { Amylase } 3300 \text { unit } \\
\text { Lipase } 2950 \text { unit } \\
\text { Protease } 160 \text { unit }\end{array}$ \\
\hline Pancrex V capsules & & $\begin{array}{l}\text { Amylase } 9000 \text { unit } \\
\text { Lipase } 8000 \text { unit } \\
\text { Protease } 430 \text { unit }\end{array}$ \\
\hline
\end{tabular}

PERT, pancreatic enzyme replacement therapy.

bone disease as per national guidelines. It is unknown whether other causes of secondary PEI lead to reduced bone mineral density, and therefore, assessment using the fracture risk assessment tool (FRAX) score and relevant National Osteoporosis guideline group (NOGG) guidance should be sought. ${ }^{64}$

Modifiable risk factors such as alcohol intake and smoking should be addressed to reduce the risk of further deterioration in exocrine pancreatic function. Management of the underlying disease in secondary PEI is also important as some forms of secondary PEI may improve over time. ${ }^{34}$ Patients with any type of PEI should be followed up with assessment of treatment on symptoms, weight and other nutritional markers, micronutrients, support with risk factor management and metabolic bone health monitoring.

\section{SUMMARY}

Low Fel-1 results are commonly found in routine gastroenterology practice, but this alone does not confirm a diagnosis of PEI. Further investigation to determine the cause of a low Fel-1 including risk factor assessment, cross-sectional imaging and classification of whether there is primary or secondary PEI is required. Management includes the use of PERT, screening for metabolic bone disease and treatment of associated disorders. Early diagnosis is important as treatment with PERT alleviates symptoms, improves 
quality of life and helps prevent long-term complications related to fat malabsorption.

Contributors JL received the commissioning to prepare the manuscript. KWL wrote the initial draft. JL and KWL wrote the final version of the manuscript. JL is the guarantor.

Funding The authors have not declared a specific grant for this research from any funding agency in the public, commercial or not-for-profit sectors.

Competing interests JL has acted as a consultant for Mylan.

Patient consent for publication Not required.

Provenance and peer review Commissioned; externally peer reviewed.

\section{ORCID iD}

John Leeds http://orcid.org/0000-0002-5140-6225

\section{REFERENCES}

1 Arasaradnam RP, Brown S, Forbes A, et al. Guidelines for the investigation of chronic diarrhoea in adults: British Society of Gastroenterology, 3rd edition. Gut 2018;67:1380-99.

2 Glasbrenner B, Kahl S, Malfertheiner P. Modern diagnostics of chronic pancreatitis. Eur J Gastroenterol Hepatol 2002;14:935-41.

3 Sziegoleit A. A novel proteinase from human pancreas. Biochem J 1984;219:735-42.

4 Stein J, Jung M, Sziegoleit A, et al. Immunoreactive elastase I: clinical evaluation of a new noninvasive test of pancreatic function. Clin Chem 1996;42:222-6.

5 Chowdhury RS, Forsmark CE. Review article: pancreatic function testing. Aliment Pharmacol Ther 2003;17:733-50.

6 Löser C, Möllgaard A, Fölsch UR. Faecal elastase 1: a novel, highly sensitive, and specific tubeless pancreatic function test. Gut 1996;39:580-6.

7 Walkowiak J, Lisowska A, Przyslawski J, et al. Faecal elastase-1 test is superior to faecal lipase test in the assessment of exocrine pancreatic function in cystic fibrosis. Acta Paediatr 2004;93:1042-5.

8 Perri F, Clemente R, Festa V, et al. Pancreatic exocrine function tests. Scand J Gastroenterol 1998;33:1118-20.

9 Glasbrenner B, Schön A, Klatt S, et al. Clinical evaluation of the faecal elastase test in the diagnosis and staging of chronic pancreatitis. Eur J Gastroenterol Hepatol 1996;8:1117-20.

10 Fischer B, Hoh S, Wehler M, et al. Faecal elastase-1: lyophilization of stool samples prevents false low results in diarrhoea. Scand J Gastroenterol 2001;36:771-4.

11 Vanga RR, Tansel A, Sidiq S, et al. Diagnostic performance of measurement of fecal elastase- 1 in detection of exocrine pancreatic insufficiency: systematic review and meta-analysis. Clin Gastroenterol Hepatol 2018;16:1220-8.

12 Campbell JA, Sanders DS, Francis KA, et al. Should we investigate gastroenterology patients for pancreatic exocrine insufficiency? A dual centre UK study. J Gastrointestin Liver Dis 2016;25:303-9.

13 Doerr W. [Pathogenesis of acute and chronic pancreatitis]. Verh Dtsch Ges Inn Med 1964;70:718-58.

14 Olsen TS. The incidence and clinical relevance of chronic inflammation in the pancreas in autopsy material. Acta Pathol Microbiol Scand A 1978;86A:361-5.

15 Struyvenberg MR, Martin CR, Freedman SD. Practical guide to exocrine pancreatic insufficiency - breaking the myths. $B M C$ Med 2017;15:29.

16 Martínez-Moneo E, Stigliano S, Hedström A, et al. Deficiency of fat-soluble vitamins in chronic pancreatitis: a systematic review and meta-analysis. Pancreatology 2016;16:988-94.

17 Talley NJ, Holtmann G, Nguyen QN, et al. Undiagnosed pancreatic exocrine insufficiency and chronic pancreatitis in functional GI disorder patients with diarrhea or abdominal pain. J Gastroenterol Hepatol 2017;32:1813-7.

18 Leeds JS, Hopper AD, Sidhu R, et al. Some patients with irritable bowel syndrome may have exocrine pancreatic insufficiency. Clin Gastroenterol Hepatol 2010;8:433-8.

19 Bellin MD, Whitcomb DC, Abberbock J, et al. Patient and disease characteristics associated with the presence of diabetes mellitus in adults with chronic pancreatitis in the United States. Am J Gastroenterol 2017;112:1457-65.

20 Luaces-Regueira M, Iglesias-García J, Lindkvist B, et al. Smoking as a risk factor for complications in chronic pancreatitis. Pancreas 2014;43:275-80.

21 Teich N, Mohl W, Bokemeyer B, et al. Azathioprine-Induced acute pancreatitis in patients with inflammatory bowel Diseases-A prospective study on incidence and severity. $J$ Crohns Colitis 2016;10:61-8.

22 Hamwi A, Veitl M, Maenner G, et al. Pancreatic elastase 1 in stool: variations within one stool passage and individual changes from day to day. Wien Klin Wochenschr 2000;112:325.

23 NICE. Pancreatic cancer in adults: diagnosis and management. NICE guideline [NG85], 2018. Available: www.nice.org.uk/ guidance/ng85

24 Löhr J.-M., Panic N, Vujasinovic M, et al. The ageing pancreas: a systematic review of the evidence and analysis of the consequences. J Intern Med 2018;283:446-60.

25 Alexandre-Heymann L, Mallone R, Boitard C, et al. Structure and function of the exocrine pancreas in patients with type 1 diabetes. Rev Endocr Metab Disord 2019;20:129-49.

26 Pancreatitis PR. Secretin increases the diagnostic yield of MRCP. Nat Rev Gastroenterol Hepatol 2014;11:519-20.

27 Dronamraju S, Scott J, Oppong K, et al. Diagnostic yield of secretin-enhanced magnetic resonance cholangiopancreatography in the investigation of patients with acalculous biliary pain. Ann Gastroenterol 2016;29:36772.

28 Krishna SG, Rao BB, Ugbarugba E, et al. Diagnostic performance of endoscopic ultrasound for detection of pancreatic malignancy following an indeterminate multidetector CT scan: a systemic review and meta-analysis. Surg Endosc 2017;31:4558-67.

29 Catalano MF, Sahai A, Levy M, et al. EUS-based criteria for the diagnosis of chronic pancreatitis: the Rosemont classification. Gastrointest Endosc 2009;69:1251-61.

30 Deprez P, Sempoux C, Van Beers BE, et al. Persistent decreased plasma cholecystokinin levels in celiac patients under glutenfree diet: respective roles of histological changes and nutrient hydrolysis. Regul Pept 2002;110:55-63.

31 Wahab PJ, Hopman WPM, Jansen JBMJ. Basal and fatstimulated plasma peptide YY levels in celiac disease. Dig Dis Sci 2001;46:2504-9.

32 Carroccio A, Iacono G, Montalto G, et al. Pancreatic enzyme therapy in childhood celiac disease. A double-blind prospective randomized study. Dig Dis Sci 1995;40:2555-60.

33 Leeds JS, Hopper AD, Hurlstone DP, et al. Is exocrine pancreatic insufficiency in adult coeliac disease a cause of persisting symptoms? Aliment Pharmacol Ther 2007;25:26571.

34 Evans KE, Leeds JS, Morley S, et al. Pancreatic insufficiency in adult celiac disease: do patients require long-term enzyme supplementation? Dig Dis Sci 2010;55:2999-3004.

35 Chen Y-L, Hsu C-W, Cheng C-C, et al. Increased subsequent risk of inflammatory bowel disease association in patients with chronic pancreatitis: a nationwide population-based cohort study. Curr Med Res Opin 2017;33:1077-82.

36 Barthet M, Lesavre N, Desplats S, et al. Frequency and characteristics of pancreatitis in patients with inflammatory bowel disease. Pancreatology 2006;6:464-71. 
37 Maconi G, Dominici R, Molteni M, et al. Prevalence of pancreatic insufficiency in inflammatory bowel diseases. assessment by fecal elastase-1. Dig Dis Sci 2008;53:262-70.

38 Henderson JR, Daniel PM, Fraser PA. The pancreas as a single organ: the influence of the endocrine upon the exocrine part of the gland. Gut 1981;22:158-67.

39 American Diabetes Association. Diagnosis and classification of diabetes mellitus. Diabetes Care 2014;37:S81-90.

40 El Ne Wihi H, Dooley CP, Saad C. Impaired exocrine pancreatic function in diabetics with diarrhoea and peripheral neuropathy. Dig Dis Sci 1988;33:705-10.

41 Dyck WP, Rudick J, Hoexter B, et al. Influence of glucagon on pancreatic exocrine secretion. Gastroenterology 1969;56:531-7.

42 Mally MI, Cirulli V, Hayek A, et al. Ica69 is expressed equally in the human endocrine and exocrine pancreas. Diabetologia 1996;39:474-80.

43 Sanvito F, Nichols A, Herrera PL, et al. Tgf-Beta 1 overexpression in murine pancreas induces chronic pancreatitis and, together with TNF-alpha, triggers insulin-dependent diabetes. Biochem Biophys Res Commun 1995;217:1279-86.

44 Kobayashi T, Nakanishi K, Kajio H, et al. Pancreatic cytokeratin: an antigen of pancreatic exocrine cell autoantibodies in type 1 (insulin-dependent) diabetes mellitus. Diabetologia 1990;33:363-70.

45 Hardt PD, Hauenschild A, Nalop J, et al. High prevalence of exocrine pancreatic insufficiency in diabetes mellitus. A multicenter study screening fecal elastase 1 concentrations in 1,021 diabetic patients. Pancreatology 2003;3:395-402.

46 Nunes ACR, Pontes JM, Rosa A, et al. Screening for pancreatic exocrine insufficiency in patients with diabetes mellitus. Am J Gastroenterol 2003;98:2672-5.

47 Icks A, Haastert B, Giani G, et al. Low fecal elastase-1 in type I diabetes mellitus. Z Gastroenterol 2001;39:823-30.

48 Rathmann W, Haastert B, Icks A, et al. Low faecal elastase 1 concentrations in type 2 diabetes mellitus. Scand J Gastroenterol 2001;36:1056-61.

49 Leeds JS, Hadjivassiliou M, Tesfaye S, et al. Lower gastrointestinal symptoms are associated with worse glycemic control and quality of life in type 1 diabetes mellitus. BMJ Open Diab Res Care 2018;6:e00514.

50 Ewald N, Bretzel RG, Fantus IG, et al. Pancreatin therapy in patients with insulin-treated diabetes mellitus and exocrine pancreatic insufficiency according to low fecal elastase 1 concentrations. Results of a prospective multi-centre trial. Diabetes Metab Res Rev 2007;23:386-91.

51 Nakamura T, Kikuchi H, Takebe K, et al. Correlation between bile acid malabsorption and pancreatic exocrine dysfunction in patients with chronic pancreatitis. Pancreas 1994;9:580-4.
52 Kotler DPet al. Enteropathy associated with the acquired immunodeficiency syndrome. Ann Intern Med 1984;101:421-8.

53 Carroccio A, Di Prima L, Di Grigoli C, et al. Exocrine pancreatic function and fat malabsorption in human immunodeficiency virus-infected patients. Scand J Gastroenterol 1999;34:729-34.

54 Carroccio A, Guarino A, Zuin G, et al. Efficacy of oral pancreatic enzyme therapy for the treatment of fat malabsorption in HIV-infected patients. Aliment Pharmacol Ther 2001;15:1619-25.

55 Price DA, Schmid ML, Ong ELC, et al. Pancreatic exocrine insufficiency in HIV-positive patients. HIV Med 2005;6:336.

56 Rothenbacher D, Löw M, Hardt PD, et al. Prevalence and determinants of exocrine pancreatic insufficiency among older adults: results of a population-based study. Scand J Gastroenterol 2005;40:697-704.

57 Herzig K-H, Purhonen A-K, Räsänen KM, et al. Fecal pancreatic elastase-1 levels in older individuals without known gastrointestinal diseases or diabetes mellitus. BMC Geriatr 2011;11:4.

58 Vujasinovic M, Valente R, Thorell A, et al. Pancreatic exocrine insufficiency after bariatric surgery. Nutrients 2017;9:E1241.

59 Armbrecht U, Lundell L, Stockbrügger RW. The benefit of pancreatic enzyme substitution after total gastrectomy. Aliment Pharmacol Ther 1988;2:493-500.

60 Leeds JS, Oppong K, Sanders DS. The role of fecal elastase-1 in detecting exocrine pancreatic disease. Nat Rev Gastroenterol Hepatol 2011;8:405-15.

61 D'Haese JG, Ceyhan GO, Demir IE, et al. Pancreatic enzyme replacement therapy in patients with exocrine pancreatic insufficiency due to chronic pancreatitis: a 1-year disease management study on symptom control and quality of life. Pancreas 2014;43:834-41.

62 Domínguez-Muñoz JE, Iglesias-García J, Iglesias-Rey M, et al. Effect of the administration schedule on the therapeutic efficacy of oral pancreatic enzyme supplements in patients with exocrine pancreatic insufficiency: a randomized, three-way crossover study. Aliment Pharmacol Ther 2005;21:993-1000.

63 Domínguez-Muñoz JE. Pancreatic enzyme therapy for pancreatic exocrine insufficiency. Curr Gastroenterol Rep 2007;9:116-22.

64 Kanis JA, Johnell O, Oden A, et al. FRAX ${ }^{\mathrm{TM}}$ and the assessment of fracture probability in men and women from the UK. Osteoporos Int 2008;19:385-97.

65 Etemad B, Whitcomb DC. Chronic pancreatitis: diagnosis, classification, and new genetic developments.. Gastroenterology 2001;120:682-707. 